\title{
Homocysteine Acid Measurement
}

National Cancer Institute

\section{Source}

National Cancer Institute. Homocysteine Acid Measurement. NCI Thesaurus. Code C74741.

The determination of the amount of homocysteine amino acid present in a sample. 